\title{
可见光促进铜催化的唑类化合物不对称烷基化
}

\author{
李祥盛刘 强* \\ (兰州大学化学化工学院 功能有机分子化学国家重点实验室 兰州 730000)
}

\section{Enantioselective Alkylation of Azoles by Merging Visible Light and Copper Catalysis}

\author{
Li, Xiangsheng Liu, Qiang* \\ (State Key Laboratory of Applied Organic Chemistry, College of Chemistry and Chemical Engineering, \\ Lanzhou University, Lanzhou 730000)
}

直接在杂芳烃酸性 $\mathrm{C}-\mathrm{H}$ 键引入烷基, 是一种原子 经济性高、步骤简单的合成方法，其产物烷基化的杂芳 烃在生物学、药学和材料学等领域具有重要应用. 近年 来, 通过不饱和卤代烃在杂芳烃酸性 $\mathrm{C}-\mathrm{H}$ 键上直接芳 基化、烯基化和炔基化的研究已经取得了很好进展，但 杂芳烃的直接烷基化反应, 由于相应卤代烷烃在反应中 容易发生诸如 $\beta-\mathrm{H}$ 消除、还原脱卤和自身偶联等副反应, 仍然具有一定的挑战性 ${ }^{[1]}$. 为解决上述问题, 一些利用 贵金属催化和引入导向基的策略被用于提高卤代烃与 杂芳烃交叉偶联的反应活性和选择性 ${ }^{[2]}$.

铜盐廉价易得, 其配合物结构丰富多变, 具有独特 的催化性能，在金属催化和可见光催化领域备受关注. 2012 年, Hu 课题组 ${ }^{[3]}$ 报道了利用铜配合物催化唑类化合 物与苠基澳的偶联反应. 2016 年, Ohmiya 课题组 ${ }^{[4]}$ 发现 在铜(I)-氮杂卡宾配体的催化体系中可温和实现烯丙基 膦对唑类化合物的对映选择性烯丙基化反应. 但铜催化 下以苄溴为原料的唑类化合物不对称烷基化反应仍然 函待开发.

可见光催化为不对称催化的发展提供了新的机 遇 ${ }^{[5]}$. 化合物经过光氧化还原循环等途径, 可在室温甚 至低温度下有效生成高活性物种, 使热反应中难以实现 的不对称催化成为可能. $\mathrm{Fu}$ 课题组 ${ }^{[6]}$ 研究表明, 手性膦 配体配位的铜(I)在可见光照射下能催化芳杂环 $\mathrm{N}-\mathrm{H}$ 对 三级卤代烃的不对称胺化反应. 这种无需额外光催化 剂, 仅通过廉价铜盐和配体实现可见光不对称催化的策 略, 虽然在合成中具备显著的高附加值, 但成功开发的 体系骞塞可数.
中国科学院上海有机化学研究所张国柱课题组近 年对铜催化高选择性反应进行了系列研究, 并且取得了 许多优异成果 ${ }^{[7]}$. 该课题组在以往的研究中发现, 使用 二苯胺基噁唑啉(BOPA)配体, 可以实现光诱导铜催化 烯烃的烷基/芳基炔基化反应，并且炔基的引入具有很 高的对映选择性 ${ }^{[\mathrm{b}]}$, 他们推测, 光激发的手性阴离子, 即激发态的 $\mathrm{N}, \mathrm{N}, \mathrm{N}-\mathrm{Cu}$ 配合物, 可以在温和的条件下, 通过单电子还原活化烷基澳, 产生烷基自由基, 进而形 成碳一碳键.

基于该课题组对铜催化领域的工作积累, 最近他们 报道了一种可见光促进铜催化的方法, 实现了唑类化合 物 2-位高效不对称烷基化 ${ }^{[8]}$. 在该工作中, 作者利用原 位生成的 $\left[t-\mathrm{BuCbzBox}-\mathrm{Cu}^{\mathrm{I}}\right]^{+}$络合物, 既作为光敏剂前体 又作为手性催化剂, 专一地产生不对称烷基化唑类化合 物

作者选用苯并噁唑和(1-溴乙基)苯为底物进行条件 篎选, 发现以二氯乙烷(DCE)作为溶剂, 使用 $\mathrm{CuI}$ 和 $t$-BuCbzBox (L3)催化体系, $t$-BuOLi 为碱, $-10{ }^{\circ} \mathrm{C}$ 下蓝 色 LED 灯照射 $48 \mathrm{~h}$, 以 $75 \%$ 的核磁产率和 $90 \%$ 的 ee 值 得到偶联产物(Scheme 1). 其中铜盐、配体和碱是反应 发生的必要条件, 可见光照射能促进产率大幅提高.

随后，作者对反应的底物范围进行了考察(Scheme $2)$. 对于(1-溴乙基)苯衍生物的底物范围, 含有不同长 度烷基链的底物以及链末端有不同取代基的底物，都有 良好的耐受性 $(3 a 、 3 b)$. 对于芳环上有不同取代基的芐 澳类化合物而言, 众多底物都能以良好的收率和优秀的 $e e$ 值得到产物, 邻甲基取代产物更是达到 $99.4 \% e e$ 值

* Corresponding author. E-mail: liuqiang@1zu.edu.cn. Published online January 8, 2021. 


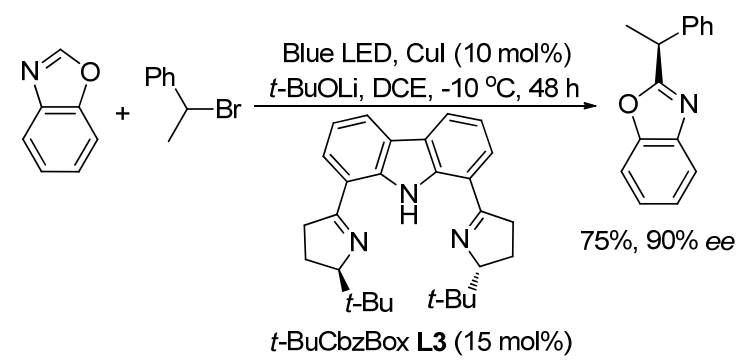

图 1 光促铜催化唑类化合物不对称烷基化的最优条件 Scheme 1 Optimal reaction conditions of light-promoted copper-catalyzed enantioselective alkylation of azoles

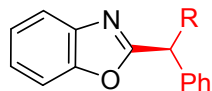

$3 \mathrm{a} \mathrm{R}=\mathrm{CH}_{2} \mathrm{CH}_{2} \mathrm{Ph} 72 \%, 88 \%$ ee 3b R $=\mathrm{CH}_{2}\left(\mathrm{CH}_{2}\right)_{3} \mathrm{Cl} 69 \%$, 97\% ee

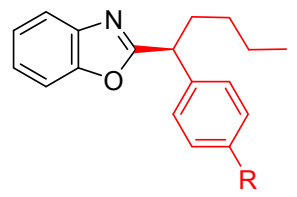

$3 c \mathrm{R}=\mathrm{C}\left(\mathrm{CH}_{3}\right)_{3} 66 \%, 90 \%$ ee 3d $\mathrm{R}=\mathrm{F} \quad 69 \%, 78 \%$ ee

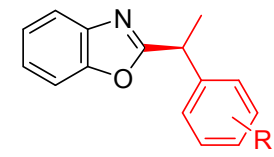

$3 e \mathrm{R}=m-\mathrm{CF}_{3} \quad 41 \%, 74 \%$ ee 3f $\mathrm{R}=\mathrm{o}-\mathrm{CH}_{3} \quad 72 \%, 99 \%$ ee

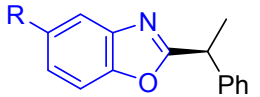

3i $\mathrm{R}=\mathrm{F} 71 \%, 85 \%$ ee 3j $\mathrm{R}=\mathrm{CH}_{3} 75 \%, 90 \%$ ee

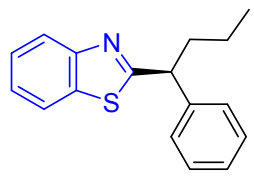

31

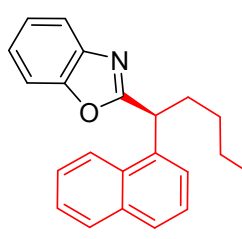

$3 \mathrm{~g}$ $61 \%, 95 \%$ ee

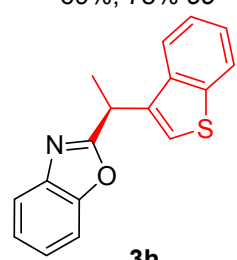

$80 \%, 88 \%$ ee
$69 \%, 83 \%$ ee

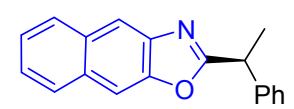

3k $68 \%, 87 \%$ ee

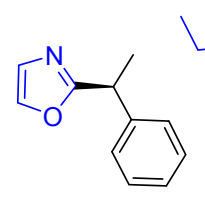

$3 \mathbf{m}$

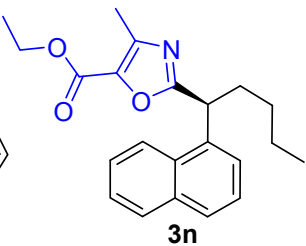

$48 \%, 92 \%$ ee

图 2 (1-溴乙基)苯衍生物的范围

Scheme 2 Scope of (1-bromoethyl)benzene derivatives

$(\mathbf{3 c} \sim 3 f)$. 将苯环替代为菜环 $(\mathbf{3 g})$ 或芳杂环 $(\mathbf{3 h})$, 也能得 到很高 $e e$ 值. 对于唑类化合物的底物范围, 作者尝试了 吸电子基、给电子基取代的苯并噁唑 $(\mathbf{3 i} 、 3 \mathbf{j})$ 、萘并啞唑 (3k)、苯并噻唑 $(3 \mathrm{l}) 、$ 啞唑 $(3 \mathrm{~m})$ 以及 5 -乙氧基羰基啞唑 $(3 \mathrm{n})$ 等, 这些底物都能以中等收率和良好甚至优秀的 $e e$ 值 得到偶联产物.

在机理探究中, 作者通过一系列氝代实验、自由基 捕获实验及光谱学实验等, 提出了可能的反应历程 (Scheme 3): 在碱的作用下, 碘化亚铜和配体 $\mathbf{L}$ 作用原 位形成 $[\mathbf{L C u}]$ (A)配合物, 该配合物与 $\left[\mathrm{Li}^{+}\right.$azole $\left.{ }^{-}\right]$转金属

化生成 $[\mathbf{L C u}-\text { azole }]^{-} \mathrm{Li}^{+}$(B), B 作为光催化剂被光照激 发生成 $[\mathbf{L C u}-\mathrm{azole}]^{-*} \mathrm{Li}^{+}(\mathbf{C})$, 然后将电子传递给烷基 溴化物得到 [ $\mathrm{LCu}^{\mathrm{II}}$-azole $]\left[\mathrm{R}^{\circ}\right](\mathbf{D})$, 后者通过对映选择性 自由基捕获, 快速转变为手性 $\mathrm{Cu}^{\mathrm{III}}$ 物种 $\mathbf{E}$, 随后经还原 消除得到产物.

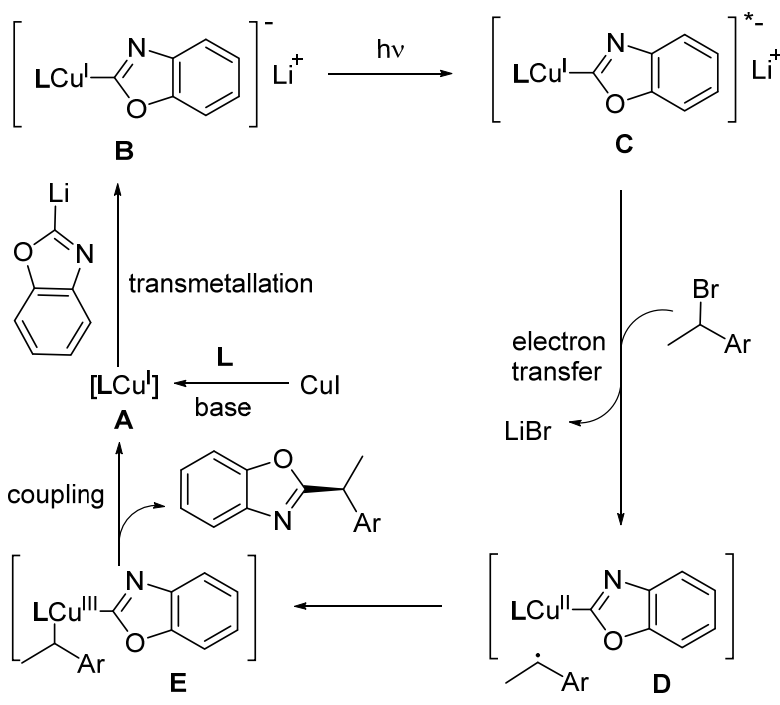

图 3 可能的反应机理

Scheme 3 Proposed reaction mechanism

综上所述，张国柱课题组报道了在温和的条件下可 见光促进的铜 CbzBox 配合物催化的唑类化合物 $\mathrm{C}-\mathrm{H}$ 键的不对称烷基化反应. 该系统引入了将可见光光氧化 还原催化剂同铜催化的 $\mathrm{C}-\mathrm{H}$ 键的不对称官能化结合的 概念: 单个的铜 CbzBox 配合物作为光和手性催化剂. 该策略具有专一的化学选择性和优异的立体选择性、温 和的反应条件和良好的底物普适性，为唑类化合物的不 对称烷基化后修饰提供了潜在的方法.

\section{References}

[1] Rudolph, A.; Lautens, M. Angew. Chem., Int. Ed. 2009, 48, 2656.

[2] Ackermann, L.; Novak, P. Org. Lett. 2009, 11, 4966.

[3] Ren, P.; Salihu, I.; Scopelliti, R.; Hu, X. Org. Lett. 2012, 14, 1748.

[4] Ohmiya, H.; Zhang, H.; Shibata, S.; Harada, A.; Sawamura, M. Angew. Chem., Int. Ed. 2016, 55, 4777.

[5] (a) Liu, Q.; Wu, L.-Z. Natl. Sci. Rev. 2017, 4, 359 (b) Chen, Y.; Lu, L.-Q.; Yu, D.-G.; Zhu, C.-J.; Xiao, W.-J. Sci. China: Chem. 2019, 62, 24.

[6] Kainz, Q. M.; Matier, C. D.; Bartoszewicz, A.; Zultanski, S. L.; Peters, J.C.; Fu, G. C. Science 2016, 351, 681.

[7] (a) Mo, X.-L.; Chen, B.; Zhang, G.-Z. Angew. Chem., Int. Ed. 2020 59,13998

(b) Zhang, Y.-J.; Sun, Y.-W.; Chen, B.; Xu, M.-C.; Li, C.; Zhang, D.-Y.; Zhang, G.-Z. Org. Lett. 2020, 22, 1490.

[8] Li, C.; Chen, B.; Ma, X.-D.; Mo, X.-L.; Zhang, G.-Z. Angew. Chem., Int. Ed. 2021, 60, 2130. 